\title{
EVALUATION OF BALLOON TAMPONADE OF THE ABDOMINAL AORTA
}

\author{
An Adjunct to the Treatment of Hemorrhagic Shock
}

HERBERT A. BERKOFF, M.D., ERNES'l W. CARPENTER, M.D., CHARLES F. FREY, M.D.

Simple, yet effective methods for emergency treatment and control of intra-abdominal hemorrhage have long been sought without apparent success. The following Part I of a two part experiment is intended to evaluate the efficacy of a percutaneously inserted intra-aortic, infra-diaphragmatic balloon tamponade for this purpose. Part II of our experiment is concerned with the morbidity and mortality associated with the use of the catheter balloon. The sequelae of aortic clamping above the coeliac artery in dog and man were reviewed. Total occlusion for more than 30 minutes was associated with hind limb paralysis and death in ever increasing proportion as the occlusion time increased [1-4].

\section{MATERIALS AND METHODS-PART I}

Our objective was to determine the most effective method of reducing intra-abdominal hemorrhage by intra-aortic balloon tamponade by means other than continuous occlusion.

\section{Group A}

Thirteen mongrel dogs weighing 15 to $24 \mathrm{~kg}$. were anesthetized using sodium pentobarbital. A triple lumen balloon catheter (Fig. 1) was inserted via cut down into the $(\mathrm{R})$ common femoral artcry and advanced to the level of the diaphragm. The abdomen was opened and

From the Department of Surgery (Section of General Surgery), University of Michigan Medical Center, Ann Arbor, Michigan 48104.

'This work was supported by the Highway Safety Research Institute, University of Michigan, Ann Arbor, Michigan 48104. the position of the catheter below the level of the diaphragm verified ( $\mathrm{T}-12)$. Balloon tamponade at this level reduced blood flow in all distal visceral vessels. This reduction in blood flow below the balloon could be demonstrated angiographically. The triple lumen catheter permitted measurement of the blood pressure above and below the balloon via Statham strain gages connected to a Honey/Well recorder.

Three separate bleeding sites were produced.

\section{Group I}

Horizontal incision $2^{\prime \prime}$ long and at least $1^{\prime \prime}$ deep was made on the anterior surface of the spleen. Prompt, brisk bleeding resulted which was aspirated from the peritoneal cavity by two suction catheters placed so that all blood was retrieved and measured. After one minute of free intra-peritoneal bleeding, the catheter balloon was inflated so that no blood pressure was obtainable distal to it. This position was maintained for one minute and again blood loss during this period measured. The above sequence of one minute balloon release followed by one minute balloon tamponade was repeated for a total of 4-8 sequences lasting a total of 8-16 minutes. Along with the measurements of blood loss, blood pressure above and below the inflated balloon was continuously monitored.

\section{Group II}

Same as Group I except the site of blecding was a two inch laceration on the anterior surface of the (L) kidney. 


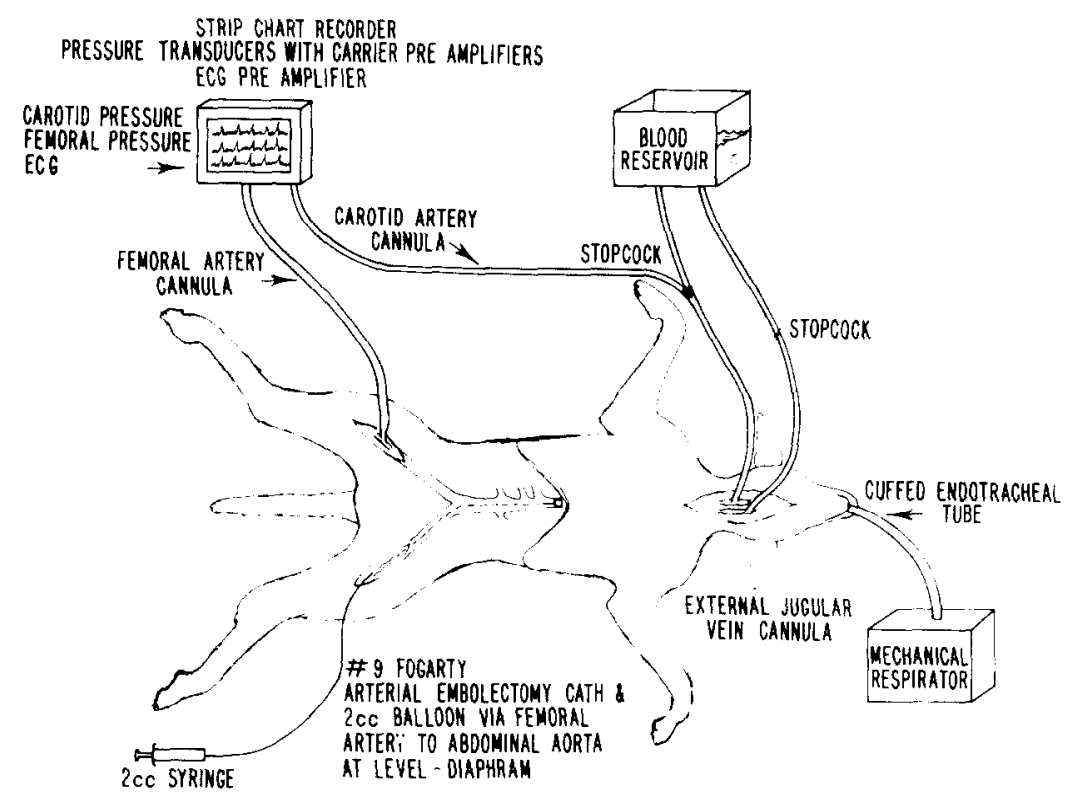

Figure 1

\section{Group III}

Same as Groups I and II except the site of bleeding was a two inch laceration on the anterior surface of the right lobe of the liver.

\section{Results}

The above lesions each caused bleeding which initially ranged from 36 to $165 \mathrm{ml} / \mathrm{min}$. After the balloon was inflated the blood loss the following minute was markedly diminished so that blood loss was reduced to 1 to $31 \mathrm{ml} /$ min. Over ensuing periods of balloon occlusion blood loss continued to decline. Successively with each period of balloon release, the amount of blood loss steadily decreased (Table 1).

\section{Group B}

Group B was similar to Group A except the balloon tamponade was extended to 5 minutes rather than the one minute of Group $\mathrm{A}$. The period of balloon deflation was constant at one minute in both Groups A \& B. Five of the larger dogs were anesthetized and monitored as in Group A. However, in 8 dogs the catheter was too large to be inserted into the femoral ressels. Instead, a 6 Fogarty thrombectomy catheter was used as the balloon tamponade and monitoring above and below the balloon was accomplished via polyethylene catheters placed into the $(\mathrm{L})$ carotid and the $(\mathrm{L})$ femoral arteries.

Four separate bleeding sites were produced.

\section{Group $I$}

A horizontal incision $2^{\prime \prime}$ long and at least $1^{\prime \prime}$ deep was made in the anterior surface to the spleen. Bleeding was aspirated as previously described in Experiment A.

\section{Group II}

Same as Group I except the site of bleeding was a two inch laceration on the anterior surface of the (L) kidney.

\section{Group III}

Same as Group I and II except the site of bleeding was a two inch laceration on the anterior surface of the $(R)$ lobe of the liver.

\section{Group IV}

Same as Groups I, II, and III except the (L) colic artery was transected and allowed to bleed freely.

The above lesions each caused hemorrhage which ranged in rate from $20-150 \mathrm{ml} / \mathrm{min}$. 
Table 1. One Minule Balloon Inflation Followed by One Minule Balloon Defation Successively for 8-16 Minutes

\begin{tabular}{|c|c|c|c|c|}
\hline & & $\begin{array}{l}\text { Total-All } \\
\text { Periods } \\
\text { Balloon } \\
\text { Inflation Each } \\
\text { Period One } \\
\text { Minute ml } \\
\text { Blood Loss }\end{array}$ & $\begin{array}{c}\text { Total-All } \\
\text { Periods } \\
\text { Balloon } \\
\text { Deflation } \\
\text { Each Period } \\
\text { One Minute ml } \\
\text { Blood Loss }\end{array}$ & $\begin{array}{c}\% \\
\text { Decrease } \\
\text { Blood Loss }\end{array}$ \\
\hline $\begin{array}{l}\text { Spleen } \\
\text { dogs) }\end{array}$ & $(3$ & 104 & 537 & $81 \%$ \\
\hline $\begin{array}{r}\text { Kidney } \\
\text { dogs) }\end{array}$ & $(5$ & 135 & 881 & $84.5 \%$ \\
\hline $\begin{array}{l}\text { Liver } \\
\text { dogs) }\end{array}$ & $(5$ & 352 & 1168 & $69.9 \%$ \\
\hline
\end{tabular}

After the balloon was inflated, the blood loss over each 5 minute period of balloon occlusion was nearly zero. During periods of balloon expansion the arterial blood pressure below the level of occlusion fell to zero, while the pressure proximal to the balloon rose and was maintained throughout the period of occlusion. During the periods of balloon release the amount of blood loss steadily decreased until it reached it's lowest level at approximately one hour (Table 2 ).

\section{Results}

The percentage of reduction of blood loss achieved by intermiltent balloon tamponade measured at the end of an hour was as follows: Seventy-84\% for dogs sustaining liver lacerations, 83-92\% for splenic lacerations, $82-96 \%$ for the major vessel lacerations and $37-79 \%$ for the kidney lacerations. These figures are the percent of reduction of bleeding and so represent the effectiveness of the intermittent balloon occlusion method in reducing blood loss. With the exception of one case, (37\% reduction in one dog in kidney group) balloon tamponade reduced blood loss from liver, splenic, and kidney injury by $70 \%$ or more in each category of injury.

\section{Discussion}

Intra-aortic balloon tamponade employing a 5 minute period of occlusion and one minute of release is an effective, simple and especially quick method of reducing intra-abdominal bleeding and maintaining cercbral blood flow.
The five minute period of occlusion and onc minute release is a more effective method of reducing blood loss from the abdominal viscera over a longer period of time than the method of alternately, expanding, and releasing the balloon every minute. The balloon tamponade decreases distal flow in the aorta and it's visceral branches promoting stasis and clot formation in the severed vessels. By the time an hour has elapsed, blood loss occurring with balloon decompression diminishes to that of balloon expansion. During early periods of balloon decompression some clots are probably washed away, however, some remain and with further balloon expansion accumulate creating an effective barrier to further bleeding.

\section{PART II}

Having demonstrated that the intra-aortic balloon catheter is an effective means of reducing blood loss from intra-abdominal injury, Part II of our experiment was designed to examine the morbidity and mortality of its use in the dog.

Twenty-five mongrel dogs weighing 10-24 kgs. were subjected to splenectomy. After a recovery period of not less than seven days, baseline determinations of hematocrit, SGOT,

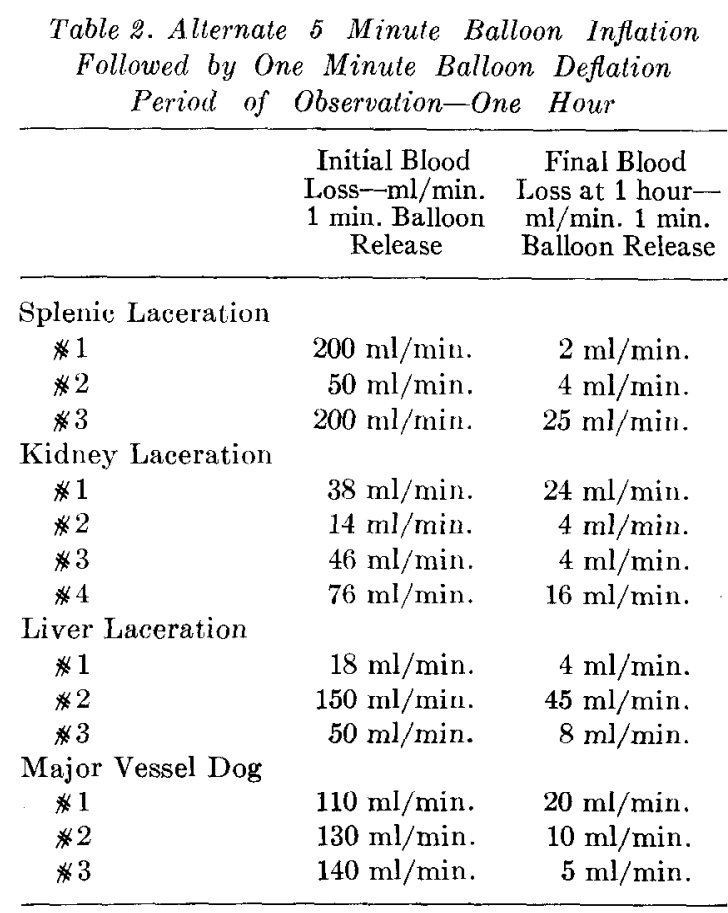


and BUN wcre performed. The animals were lightly anesthetized with sodium pentobarbital (a) $30 \mathrm{mgm} / \mathrm{kg}$ of body weight, intubated, and placed on a Harvard volume respirator. The electrocardiogram, carotid, and femoral arterial pressures were recorded by means of arterial cannula and Statham pressure transducers. An additional catheter was placed in the Superior Vena Cava via the external jugular vein. A 9 Fogarty arterial cmbolectomy catheter was introduced via the (L) common femoral artery to the level of the xiphoid (see illustration). Arteriography was obtained with the catheter in place documenting the placement of the balloon above the level of the celiac artery.

\section{Group $I-6$ dogs}

The dogs were bled into a reservoir via the arterial route to a mean arterial Bl.P. of 50 $\mathrm{mmHg}$ and maintained at that level for 30 minutes by adding to and subtracting from the reservoir as necessary. Heparin was added to the reservoir and at the end of the period of controlled shock, the volume removed was noted and its percentage of total volume calculated on a weight basis. The Fogarty catheter balloon was then inflated with $2 \mathrm{ml}$ of water every 5 minutes. Inflation or occlusion time being four minutes. Deflation or nonocclusion time being one minute. This was continued for 30 minutes or six periods of inflation. At the end of this time, the animals blood volume was returned, the catheters removed, and the incisions closed. The dogs were returned to their pens and when awake, given food and water ad lib daily. Clinical detcrmination of neuromuscular studies as well as daily hematocrits, SGOT, and BUNS were obtained.

\section{Group $I I-3$ dogs}

By the method described in Group I the dogs were maintained at an arterial blood pressure of $50 \mathrm{mmHg}$ for 60 minutes, their heparinized blood returned and the animals followed in a like manner as in Group I.

\section{Group III-3 dogs}

Using the preparation described in Group I, but removing no blood, the balloon was in- flated for six four minute intervals over a pcriod of 30 minutes.

Group IV-4 dogs

Procedure similar to Group I except the blood was replaced prior to use of the balloon.

Group V-4 dogs

Similar to Group I except volume replacement was with Hartman's Solution rather than whole blood.

\section{Group VI-5 dogs}

Similar to Group I except where blood replacement was begun prior to inflating the balloon and not completed until the end of the 30 minute catheter inflation period.

\section{Results}

Of the 6 dogs in Group I, two died in the first 12 hours without regaining consciousness. One died at 36 hours without regaining consciousness. The remaining three survivors has a spastic paralysis of the lower extremities.

There was one spastic paralysis each in Group V and VI.

All the dogs in groups II, III, and IV were alive at the time of sacrifice 14 days following the experiment. The blood urea nitrogen and SGOT levels were normal whether the dogs lived or dicd. Postmortem tissue cxamination was significant only in the two animals that died within 12 hours after the operative procedure. Both had soft yellow livers. Microscopic examination confirmed necrosis of the hepatic parenchyma. Neither of these dogs had liver function studies following operations as both deaths occurred prior to the 12 hour collections.

\section{DISCUSSION}

Intra-aortic balloon tamponade of the infra-diaphragmatic portion of the aorta produces a rise in carotid artcry pressurc. No undesirable neurologic sequelae or alterations in kidney or liver function were noted in normotensive dogs when their aortas were tamponaded for periods up to one hour. When balloon tamponade either constant or intermittent 
over 30 minutes was preceded by 30 minutes of hypotension, death or hind limb paralysis was a frequent result. Dogs that were hypotensive and hypovolemic at the time of balloon tamponade developed complications not seen in other dogs. The paralysis seen in single dogs in Group V and VI on review of chart recordings showed they were hypotensive with the balloon deflated for greater than half the experiment.

Balloon tamponade of the aorta for four out of five minutes for periods of a half hour above the celiac no matter how convenient a method of increasing perfusion pressure of parotid and coronary vessels, and decreasing intra-abdominal hemorrhage is dangerous for dogs which have been hypotensive. In other experiments not reported here, balloon tamponade in pigs made hypotensive often results in death or hind limb paralysis. Therapeutic use of balloon tamponade of the abdominal aorta in man may have similar undesirable sequelae.

\section{SUMMARY}

Intra-aortic balloon tamponade of the infra-diaphragmatic aortic is an effective means of reducing intra-abdominal hemorrhage. However, its therapeutic use when preceeded by hypotension and in the face of persistent hypovolemia, often results in death or hind limb paralysis in dogs.

\section{REFFRENCES}

1. Blaisdell, F. W., and Cooley, D. A. Relationship of spinal fluid pressure and incidence of paraplegia following temporary aortic occlusion: an experimental study. Surgical Form. Vol. $11: 153-154,1960$.

2. Burch, B. H., Traphagen, D. W., Folkman, M. T., Rosenbaum, D. A., and Mueller, E. C. Temporary aortic occlusion in abdominal surgery. Surgery, $35: 684-689,1954$.

3. Hughes, C. W. Use of intra-aortic balloon catheter tamponade for controlling intra-abdominal hemorrhage in man. Surgery, 36:65-68, 1954.

4. Parkins, W. M., Ben, M., and Vars, H. M. Tolerance of temporary occlusion of the thoracic aorta in normothermic and hypothermic dogs. Surgery, $38: 38-47,1955$. 